\title{
Nutrition in medical education: reflections from an initiative at the University of Cambridge
}

This article was published in the following Dove Press journal:

Journal of Multidisciplinary Healthcare

2I May 2014

Number of times this article has been viewed

\section{Lauren Ball' \\ Jennifer Crowley² \\ Celia Laur ${ }^{3}$ \\ Minha Rajput-Ray ${ }^{3}$ \\ Stephen Gillam ${ }^{4}$ \\ Sumantra Ray ${ }^{3}$}

'Nutrition and Dietetics, School of Allied Health Sciences, Centre for Health

Practice Innovation, Griffith University, Queensland, Brisbane, Australia; ${ }^{2}$ Faculty of Medical and Health Sciences, University of Auckland, Auckland, New Zealand; ${ }^{3}$ Need for Nutrition Education/Innovation Programme, Medical Research Council Human Nutrition Research, Cambridge, UK; ${ }^{4}$ Department of Public Health and Primary Care, Institute of Public Health, University of Cambridge, Cambridge, UK

\section{Video abstract}

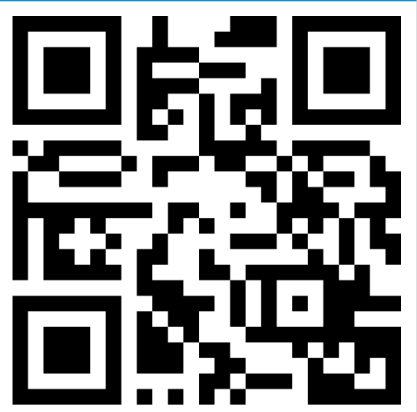

Point your SmartPhone at the code above. If you have a QR code reader the video abstract will appear. Or use: http://dvpr.es//kVdxD5

Correspondence: Sumantra Ray Need for Nutrition Education/Innovation Programme, c/o MRC Human Nutrition Research, Elsie Widdowson Laboratory,

I 20 Fulbourn Road, Cambridge

CBI 9NL, UK

Tel +44 I 223426356

Fax +44 I223437515

Email sumantra.ray@mrc-hnr.cam.ac.uk
Abstract: Landmark reports have confirmed that it is within the core responsibilities of doctors to address nutrition in patient care. There are ongoing concerns that doctors receive insufficient nutrition education during medical training. This paper provides an overview of a medical nutrition education initiative at the University of Cambridge, School of Clinical Medicine, including 1) the approach to medical nutrition education, 2) evaluation of the medical nutrition education initiative, and 3) areas identified for future improvement. The initiative utilizes a vertical, spiral approach during the clinically focused years of the Cambridge undergraduate and graduate medical degrees. It is facilitated by the Nutrition Education Review Group, a group associated with the UK Need for Nutrition Education/Innovation Programme, and informed by the experiences of their previous nutrition education interventions. Three factors were identified as contributing to the success of the nutrition education initiative including the leadership and advocacy skills of the nutrition academic team, the variety of teaching modes, and the multidisciplinary approach to teaching. Opportunities for continuing improvement to the medical nutrition education initiative included a review of evaluation tools, inclusion of nutrition in assessment items, and further alignment of the Cambridge curriculum with the recommended UK medical nutrition education curriculum. This paper is intended to inform other institutions in ongoing efforts in medical nutrition education.

Keywords: undergraduate medical education, nutrition, curriculum

\section{Introduction}

The importance of nutrition in maintaining good health is widely recognized. ${ }^{1-3}$ Landmark reports have confirmed that it is within the core responsibilities of doctors to address nutrition in patient care. ${ }^{4,5}$ Doctors commonly report insufficient knowledge and skills related to nutrition, ${ }^{6,7}$ and there are ongoing concerns that doctors receive insufficient nutrition education during medical training. ${ }^{8-11}$ Key mandates exist within countries such as the United Kingdom and United States to enhance the nutrition education received by medical students.,5,12-14 However, the integration of nutrition into medical education is a continuing challenge worldwide. For the purpose of this paper, "medical education" refers only to the study of medicine by medical students, not other health care professionals.

Factors limiting the integration of nutrition into medical education include curriculum crowding, ${ }^{15}$ scarcity of nutrition advocates and specialist teachers, ${ }^{16}$ and lack of consensus on optimal delivery and evaluation of medical nutrition education. ${ }^{8}$

The pervasive nature of nutrition creates a challenge to identify the most appropriate location for nutrition within medical curricula. Equally, this pervasiveness creates an 
opportunity to encourage interdisciplinary specialty teaching within medical education. Previous initiatives to enhance nutrition in medical education have focused on approaches to integrate nutrition into curricula ${ }^{17,18}$ as well as modes of delivery of nutrition education to students including, for example, web-based resources created to enhance student learning. ${ }^{17,19,20}$ These initiatives provide valuable information and examples to other medical institutions and facilitate ongoing development in this area of medical education. In line with this, our paper is intended to be utilized by other institutions to inform ongoing efforts in medical nutrition education.

The Need for Nutrition Education/Innovation Programme (NNEdPro) is an independent education and evaluation program that aims to equip "tomorrow's doctors" with clinically relevant, foundation nutrition and public health knowledge to enhance nutrition care in health care settings. ${ }^{21}$ In England, the University of Cambridge, Nutrition Education Review Group (NERG) is linked with NNEdPro and is comprised of doctors, dietitians, and nutritionists who are academic and research staff. The aim of the NERG is to develop, implement, and evaluate the medical nutrition education, particularly clinical and public health nutrition, provided to undergraduate and postgraduate medical students at the university. In early 2011, the University of Cambridge, School of Clinical Medicine, Department of
Public Health and Primary Care, in collaboration with the NERG, piloted a nutrition education session in the first clinical year of the undergraduate medical degree. This teaching was shaped by the early work of the NNEdPro group ${ }^{22,23}$ and was incorporated into undergraduate and graduate medical curricula following favorable evaluations.

The medical nutrition education initiative at the University of Cambridge, School of Clinical Medicine receives ongoing review and evaluation for delivery, content, and outcomes of teaching and students' nutrition knowledge, attitudes, and practices. In this paper, we provide an overview of the progress of this initiative, specifically the evolution of teaching methods; the outcome evaluation; and areas identified for future improvements.

\section{Approach to the medical nutrition education initiative}

The University of Cambridge, School of Clinical Medicine offers a 6-year undergraduate medical degree and a 4-year graduate medical degree. ${ }^{24}$ The overall aim of the medical nutrition education initiative is to increase nutrition awareness and skills of undergraduate and graduate medical students through a vertical, spiral approach which builds upon previous learning experiences. We provide an overview of

Table I Nutrition education in the undergraduate and graduate degrees at the University of Cambridge, School of Clinical Medicine

\begin{tabular}{|c|c|c|c|}
\hline $\begin{array}{l}\text { Undergraduate degree } \\
\text { (6 years; 150 students) }\end{array}$ & $\begin{array}{l}\text { Graduate degree } \\
\text { ( } 4 \text { years; } ~ 15 \text { students) }\end{array}$ & Current nutrition education & $\begin{array}{l}\text { Future nutrition education } \\
(\sim 250 \text { students by } 2017)\end{array}$ \\
\hline $\begin{array}{l}\text { YI-3 - Medical and Veterinary } \\
\text { Science Tripos (preclinical years) }\end{array}$ & $N / A^{a}$ & Minimal specified nutrition education. & $\begin{array}{l}\text { Ongoing curricular review to identify } \\
\text { opportunities for nutrition education. }\end{array}$ \\
\hline Y4 - clinical year I & YI - clinical year I & $\begin{array}{l}\text { 4-hour session (undergraduates); I.5 hour } \\
\text { session (graduates), including under } \\
\text { and over nutrition, nutrition screening, } \\
\text { and assessment. } \\
\text { Evaluated by students through a } \\
\text { questionnaire completed online before } \\
\text { and I month after the session to assess } \\
\text { nutrition knowledge, attitudes, and practices. } \\
\text { An open-ended questionnaire also collects } \\
\text { qualitative feedback from both students and } \\
\text { the teaching team for overall feedback. }\end{array}$ & $\begin{array}{l}\text { Maintain current teaching (update } \\
\text { each year). } \\
\text { Evaluation by students through a } \\
\text { quantitative questionnaire completed } \\
\text { online before and I month after } \\
\text { the session to assess attitudes and } \\
\text { confidence in nutrition care. An } \\
\text { open-ended questionnaire distributed } \\
\text { after the session to be completed by } \\
\text { students and the teaching team for } \\
\text { overall feedback. }\end{array}$ \\
\hline Y5 - clinical year $2^{\mathrm{b}}$ & $\mathrm{Y} 2$ - clinical year $2^{\mathrm{b}}$ & Minimal specified nutrition education. & $\begin{array}{l}\text { Podcasts to supplement students' } \\
\text { learning of clinical conditions and } \\
\text { diseases. These will be supported } \\
\text { by short face-to-face interactions. } \\
\text { The same questionnaire used in the } \\
\text { previous year will be administered } \\
\text { again, pre- and post-teaching. }\end{array}$ \\
\hline Y6 - clinical year 3 & Y3 - clinical year 3 & $\begin{array}{l}\text { 2-hour session on the relationship between } \\
\text { diet and disease and its application to } \\
\text { lifestyle behavior. }\end{array}$ & $\begin{array}{l}\text { Incorporation of nutrition leadership } \\
\text { into current nutrition education. The } \\
\text { same questionnaire used in } Y 4 / Y I \text { will } \\
\text { be administered pre- and post teaching. }\end{array}$ \\
\hline
\end{tabular}

Notes: a ${ }^{-}$raduate students do not complete the 3-year Medical and Veterinary Science Tripos; bundergraduate and graduate courses align from middle of clinical year. Abbreviations: $Y$, year; N/A, not applicable. 
the medical nutrition education within Cambridge medical training in Table 1.

\section{Preclinical years}

The first 3 years of the undergraduate degree are dedicated to foundation natural science courses, known as the "Tripos". Students gain a thorough understanding of the science-base underpinning medicine and health and grounding in the basic knowledge and skills necessary for working with patients. ${ }^{24}$ Within these 3 years, students cover some topics that are related to nutrition such as biochemistry and physiology. Based on students' experiences from other universities, the mode of learning is not typically recognized as "nutrition-related"; hence, it is likely that the importance of nutrition in patient care is not highlighted. ${ }^{25,26}$

\section{Clinical year I}

Students' initial exposure to medical nutrition education occurs during the first clinical year of each degree. One component of the curriculum, "Clinical and Public Health Nutrition", covers nutrition issues and their relevance to clinical practice by addressing some of the nutrition curriculum recommendations of the Academy Nutrition Group of the Academy of Medical Royal Colleges. ${ }^{27}$ The overall aim of this curriculum component is to equip students with information and resources to appropriately identify and address nutrition-related issues in the hospital setting.

For undergraduate students, the cohort is divided into two groups, each undertaking a 4-hour session. The session begins with a plenary, following which students are split into three smaller groups. Each group rotates between three "carousel-style" workshops that focus on a particular area of nutrition, with topics including under-nutrition, obesity in the hospital setting, nutrition screening and assessment, fluids and electrolytes, and others, based on tutor availability. Each workshop is facilitated by a multidisciplinary team of doctors, dietitians, nutritionists, and nurses to present nutrition-related clinical scenarios that students may encounter in training and practice and demonstrate how each health profession may contribute to providing nutrition care to patients. The sessions aim to be as interactive as possible including opportunities to taste supplements, practice patient communication, and conduct anthropometric measures on fellow students. Graduate students experience a similar session in their first clinical year. The smaller student cohort allows for efficiencies of time, with similar learning outcomes achieved in a 1-hour session also facilitated by a multidisciplinary team typically including a doctor, dietitian, and public health nutritionist.

\section{Clinical year 2}

As yet there are no specific nutrition education sessions in the second clinical year of the undergraduate and graduate degrees. However, plans have commenced to integrate nutrition into existing teaching through podcasts that supplement students' learning of clinical conditions and diseases. These podcasts will be accompanied by short face-to-face interactions which will add elements of blended learning to this component of the initiative. This is similar to the innovative online approach used in the "Nutrition in Medicine" project in the US. ${ }^{8}$

\section{Clinical year 3}

Since 2013, a nutrition education session has been included in the curriculum for students in the third clinical year of each degree. The aim of this 2-hour session is for students to develop a deeper understanding of the relationship between diet and disease and its application to lifestyle behavior, ${ }^{26}$ in line with the "preparation for practice" component of the third year curriculum. To achieve this, the session focuses on 1) noncommunicable diseases, 2) chronic disease prevention, and 3) leadership skills in nutrition. Overall, this component of the initiative aligns with the latest UK recommendations for the need to continually reinforce the importance of nutrition knowledge and skills throughout medical training. ${ }^{5}$

\section{Elective studies}

In addition to the curriculum initiative, the NERG has developed a "student selected component" for self-driven undergraduate students in their first clinical year who take a particular interest in further developing their nutrition awareness. This 5-week elective includes educational and practical components through the affiliated work of NNEdPro and hospital-based medical nutrition clinics. Students can select from four possible themes; nutrition support, obesity, public health nutrition, or nutrition research. These experiences give students the opportunity to utilize their nutrition knowledge and skills in patient care and to observe interprofessional approaches to address nutrition in clinical settings. ${ }^{26}$

\section{Evaluation of the medical nutrition education initiative}

Evaluation is an important and evolving feature of the medical nutrition education initiative at the University of Cambridge, School of Clinical Medicine. To facilitate evaluation at the initial stages, a feasibility pilot of a nutrition education session was conducted prior to its inclusion in the curriculum. Outcome 
measures were based on principles of formative evaluation. Since this time, the evaluation has focused on the nutrition education sessions within the first clinical year to ensure ongoing quality improvement with each successive session. The evaluation of these sessions has three aspects: 1) quantitative measurement of changes in students' nutrition knowledge, attitudes, and practices through a pre- and post teaching multiple-choice questionnaire; 2) qualitative feedback from students on the delivery of the workshop; and 3) peer-facilitated feedback for workshop facilitators by the NERG members.

Prior to the commencement of nutrition education teaching in the first clinical year, students are encouraged to complete an online multiple-choice questionnaire to measure nutrition knowledge, attitudes, and practices. The questionnaire has been construct-validated against key clinical learning outcomes from previous NNEdPro nutrition education interventions. ${ }^{22}$ One month after the nutrition education session, students are invited to complete the questionnaire again, and changes in the mean responses are calculated.

Overall, the changes observed in nutrition knowledge, attitudes, and practices 1 month after the nutrition education sessions are promising. For example, the proportion of responding students who strongly agreed with the item "From a public health perspective, do you think that nutrition is important in reducing the global burden of disease?" increased from $0 \%$ to $70 \%$ after the delivery of a recent session. In addition, there is often a noticeable increase in the proportion of students who appropriately respond to items on nutrition-related clinical practices. However, limitations in cohort sizes and response rates prevent further statistical analysis or interpretation of this data.

At the conclusion of nutrition education teaching in the first clinical year, students provide written feedback on the delivery and content of the workshops as well as suggestions for future improvements. Students frequently report that the workshops are comprehensive, appropriately interactive, and useful for informing future practice. Suggestions for improvements typically relate to providing more teaching time to cover additional nutritional topics, a common challenge reported within other medical schools. ${ }^{8,28,29}$ As a result, the course delivery has been appropriately modulated to allow students sufficient time to experience allocated activities.

The nutrition education in the first clinical year is also evaluated through peer-facilitated feedback by NERG team members who observe all of the workshops and collaboratively develop written feedback for workshop facilitators. The feedback includes aspects of the workshop delivery that were perceived to be successful as well as recommendations for improvement. The feedback covers issues such as workshop structure, slide format, oral delivery, body language, depth of content, interaction with students, and time management, in line with best-practice teaching in higher education. ${ }^{30}$

\section{Factors contributing to the success of the medical nutrition education initiative}

We have identified three principal factors that have contributed to the success of the medical nutrition education initiative. Firstly, strong academic leadership in nutrition and support from the wider medical faculty facilitated the trial of a nutrition education session in the first clinical year of the undergraduate medical degree, which has since become a component of the undergraduate and graduate curricula. ${ }^{31-33}$ In line with this, the NERG advisory panel and teaching faculty is comprised of senior academics in clinical and public health nutrition, which provides a strong foundation for leadership and advocacy in nutrition education. ${ }^{34}$

Secondly, the medical nutrition education initiative utilizes a variety of teaching approaches to integrate nutrition into existing content. Across the duration of the medical degrees, nutrition education will be implemented using combinations of problem-based learning, small group experiences, online learning activities, and didactic seminars. Diverse teaching modes are recommended by other institutions to successfully integrate nutrition into existing content within restricted time frames in medical education. ${ }^{28}$ The learning experiences available to students through the elective student selected component add further diversity to the teaching approaches and provide additional integration of nutrition into the existing training of students. ${ }^{26}$

Thirdly, the medical nutrition education initiative is founded on a multidisciplinary approach to nutrition teaching and practice. The NERG enlists the support of medical practitioners, dietitians, nutritionists, and nurses in the delivery and evaluation of nutrition education sessions. Multidisciplinary teaching is a key focus of education guidelines for future health professionals ${ }^{35,36}$ and is widely encouraged by other institutions to model the contribution of health professionals in addressing nutrition in patient care. ${ }^{37,38}$

\section{Continual improvement to the medical nutrition education initiative}

A challenge for medical nutrition education is the lack of consensus on the best way to develop and deliver nutrition 
education within medical training. ${ }^{8}$ As a result, the integration of nutrition into medical curricula is at the discretion of individual medical schools. ${ }^{8}$ Continual evaluation is required for all aspects of medical nutrition education initiatives to identify opportunities for improvements. ${ }^{39}$ Recently recommended approaches to enhance medical education focus on 1) practice skills, 2) continuous learning, and 3) patient care outcomes through collaborative interprofessional team work. ${ }^{40}$ In the context of nutrition education, these approaches highlight a movement towards recognizing competences required for effective practice and provide a model for universities to overcome challenges when integrating nutrition into traditional medical curricula. ${ }^{41}$

We identified three key opportunities for improvement to the medical nutrition education initiative at the University of Cambridge, School of Clinical Medicine. Firstly, we believe that the evaluation of students' nutrition competence could be enhanced in the first clinical year. Given the challenges involved in obtaining completed responses to the evaluation questionnaire, strategies to ensure that all students complete the questionnaire before and 1 month after the nutrition education sessions are recommended. These strategies may include incentives for completion of the survey or promoting the survey as a mandatory nongraded piece of assessment. In addition, the existing ten-item questionnaire was based on a previously developed tool ${ }^{42}$ which informed the questionnaire used in the early work of NNEdPro. ${ }^{22}$ Since this time, other tools such as the Nutrition in Patient Care Survey and Nutrition in Medical Education Survey have been developed ${ }^{43}$ and provide a more comprehensive investigation of students' changes in nutrition knowledge, attitudes, and practices. ${ }^{7,43-45}$ It is also important to comprehensively evaluate knowledge, attitudes, and practices as inadequacies in these areas are known to adversely impact on doctors' ability and willingness to perform nutrition counseling. ${ }^{46-48}$ Therefore, we recommended that the questionnaire is reviewed to provide an objective, in-depth investigation of students' changes in confidence and skills.

Secondly, we believe the NERG could include nutrition in written and practice-based clinical exams to drive student learning and provide additional information on students' nutrition-related competence. ${ }^{26}$ While the nutrition content is currently not assessed, preliminary discussions have occurred to incorporate nutrition into the written and practical examinations for students in their first clinical year. Incorporation of nutrition into assessments raises the profile of nutrition and reinforces the importance of nutrition in patient care to both students and academics. ${ }^{39}$ In addition, we suggest it provides a means to measure relevant indicators of nutrition-related clinical effectiveness such as nutrition knowledge, malnutrition identification, along with referral to dietitians and other health professionals.

Thirdly, the current structure of the medical nutrition education initiative utilizes a vertical, spiral approach, where students develop nutrition competence as they progress through their degree. For example, during a practical obesity session in clinical year 1 , students have the opportunity to learn and practice appropriate ways to speak with obese patients. Clinical year 3 expands on learning this through incorporating methods of applying these skill and by adapting change management and leadership techniques into their work. To continue the spiral learning process, we recommend that nutrition content is integrated into clinical year 2 and the curriculum in the preclinical years. Horizontal integration into other specialties to increase students' exposure to nutrition and interdisciplinary specialty nutrition teaching would also be encouraged. Within the preclinical years, nutrition concepts can be signposted in subjects such as biochemistry and physiology or body systems such as gastroenterology, endocrinology, hematology, oncology, and cardiovascular, pulmonary, and renal systems. Signposting is imperative to emphasize the role of diet in disease etiology and provide relevance to the nutrition received by students. ${ }^{25}$

Finally, we suggest that the current curriculum be mapped against the national recommendations of the Academy Nutrition Group of the Academy of the Medical Royal Colleges. ${ }^{27}$ Mapping the current curriculum to these recommendations will identify components of the recommended curriculum already covered and those that require inclusion after future curricula reviews. Further alignment of the current medical nutrition education with these recommendations is likely to result in comprehensive coverage of relevant nutritional areas.

\section{Conclusion}

In this paper, we have provided an overview of the progress of medical nutrition education at the University of Cambridge, School of Clinical Medicine. A vertical, spiral medical nutrition education initiative occurs during the clinically focused years of the undergraduate and graduate medical degree. We identified three factors that have contributed to the success of the initiative, which are the leadership and advocacy skills of the nutrition academic team, the variety of teaching modes, and the multidisciplinary approach to teaching and practice. We outlined opportunities for continuing improvement to the medical nutrition education initiative including review of evaluation tools, inclusion of nutrition 
in assessment items, and further alignment of the current curricula with the recommended curriculum for medical nutrition education in the UK.

\section{Acknowledgments}

The authors wish to acknowledge Dr Jeremy Woodward, Dr Adrian Park, Dr Lisa Sharkey, Serena Skeret, Carla Pearson, Mary-T Casserly, Jayshree Ramsurun, Mike van der Es, Dr Joan Gandy, Tim Eden, Jean Redmond, and Mary Ghasemi. Dr S Ray is supported primarily by the UK Medical Research Council. The teaching overseen by the NERG is funded through the University of Cambridge Public Health teaching strand.

\section{Disclosure}

The authors report no conflicts of interest in this work.

\section{References}

1. World Health Organization. Diet, Nutrition and the Prevention of Chronic Diseases. Geneva: World Health Organization; 2003. Available from: http://whqlibdoc.who.int/trs/who_trs_916.pdf. Accessed December 1, 2013.

2. Townsend P, Davison N, Whitehead M, editors. Inequalities in Health: The Black Report; The Health Divide. London: Penguin Books; 1992.

3. HealthyPeople 2020 [homepage on the Internet]. Washington, DC: United States Department of Health and Human Services. Available from: http://www.healthypeople.gov/2020/default.aspx. December 1, 2013.

4. Royal College of Physicians of London. Nutrition and Patients: A Doctor's Responsibility. London: Royal College of Physicians of London; 2002.

5. General Medical Council. Tomorrow's Doctors; Outcomes and Standards for Undergraduate Medical Education. London: General Medical Council: 2009. Available from: http://www.gmc-uk.org/TomorrowsDoctors_2009.pdf_39260971.pdf. Accessed December 1, 2013.

6. Leslie FC, Thomas S. Competent to care. Are all doctors competent in nutrition? Proc Nutr Soc. 2009;68(3):296-299.

7. Vetter ML, Herring SJ, Sood M, Shah NR, Kalet AL. What do resident physicians know about nutrition? An evaluation of attitudes, self-perceived proficiency and knowledge. J Am Coll Nutr. 2008;27(2):287-298.

8. Adams KM, Kohlmeier M, Powell M, Zeisel SH. Nutrition in medicine: nutrition education for medical students and residents. Nutr Clin Pract. 2010;25(5):471-480.

9. Kolasa KM. Developments and challenges in family practice nutrition education for residents and practicing physicians: an overview of the North American experience. Eur J Clin Nutr. 1999; 53(Suppl 2):S89-S96.

10. Cimino JA. Why can't we educate doctors to practice preventive medicine? Prev Med. 1996;25(1):63-65.

11. Haenel H. Nutrition in Medical Education. Report of the British Nutrition Foundation's Task Force on Clinical Nutrition. Herausgegeben von J. Gray. 35 Seiten, 3 Anlagen. The British Nutrition Foundation, London 1983. Preis:1,95 £. Nahrung. 1985;29:458.

12. National Research Council. Nutrition Education in US. Medical Schools. Washington, DC: The National Academies Press; 1985.

13. Council of Europe Alliance. 10 Key Characteristics for Good Nutritional Care. London, 2006. Available from: http://www.thenacc.co.uk/assets/ downloads/139/10\%20key\%20Characteritstics\%20of\%20Good\%20 Nutritional\%20Care\%20poster.pdf. Accessed April 7, 2014.
14. 101st US Congress. National Nutrition Monitoring and Related Research Act of 1990. Public law 101-445. Washington, DC: US Congress; 1990. Available from: http://www.gpo.gov/fdsys/pkg/ STATUTE-104/pdf/STATUTE-104-Pg1034.pdf. Accessed December $1,2013$.

15. Walker WA. Innovative teaching strategies for training physicians in clinical nutrition: an overview. J Nutr. 2003;133(2):541S-543S.

16. Heimburger DC. Physician-nutrition-specialist track: if we build it, will they come? Intersociety Professional Nutrition Education Consortium. Am J Clin Nutr. 2000;71(5):1048-1053.

17. Krebs NF, Primak LE. Comprehensive integration of nutrition into medical training. Am J Clin Nutr. 2006;83(4):945S-950S.

18. Taren DL, Thomson CA, Koff NA, et al. Effect of an integrated nutrition curriculum on medical education, student clinical performance, and student perception of medical-nutrition training. Am J Clin Nutr. 2001;73(6):1107-1112.

19. Underbakke G, McBride PE, Spencer E. Web-based resources for medical nutrition education. Am J Clin Nutr. 2006;83(4):951S-955S.

20. Hark L, Morrison G, editors. Medical Nutrition and Disease: A CaseBased Approach, 3rd ed. Malden, MA: Blackwell Publishing; 2003.

21. Need for Nutrition Education Programme. Five year update: the need for nutrition education programme. Perspect Public Health. 2013;133(2):78.

22. Ray S, Udumyan R, Rajput-Ray M, et al. Evaluation of a novel nutrition education intervention for medical students from across England. BMJ Open. 2012;2:e00417.

23. Ray S, Laur C, Rajput-Ray M, Gandy J, Schofield S. Planning Nutrition Education Interventions for the Medical Workforce: 'Nutrition Education Workshop for Tayside Doctors' (NEWTayDoc) A pilot project to inform development of the Need for Nutrition Education Programme (NNEdPro). Scotland: MedEdWorld; 2012. Available from: http://www.nnedpro.org.uk/wordpress/wp-content/ uploads/2013/08/PlanningNutritionEducationInterventions.pdf. Accessed December 1, 2013.

24. University of Cambridge. School of Clinical Medicine [homepage on the Internet]. Cambridge: University of Cambridge. Available from: http://www.medschl.cam.ac.uk. Accessed December 1, 2013.

25. Bringing physician nutrition specialists into the mainstream: rationale for the Intersociety Professional Nutrition Education Consortium. Am J Clin Nutr. 1998;68(4):894-898.

26. Kushner R, Van Horn L, Rock C, et al. Nutrition education in medical schools: a time of opportunity. Am J Clin Nutr. Epub 2014 March 19.

27. Academy of Medical Royal Colleges. UK Undergraduate Curriculum in Nutrition. London: ICGN Undergraduate Nutrition Education Implementation Group 2013. Available from: http://www.aomrc.org. uk/intercollegiate-group-on-nutrition/curricula.html. Accessed April 7, 2014.

28. Lindell KC, Adams KM, Kohlmeier M, Zeisel SH. The evolution of Nutrition in Medicine, a computer-assisted nutrition curriculum. Am J Clin Nutr. 2006;83(4):956S-962S.

29. Adams KM, Lindell KC, Kohlmeier M, Zeisel SH. Status of nutrition education in medical schools. Am J Clin Nutr. 2006;83(4): 941S-944S.

30. Martin GA, Double JM. Developing higher education teaching skills through peer observation and collaborative reflection. Innov Educ Train Int. 1998;35(2):161-170.

31. Le Gardeur BY, Lopez-SA. Nutrition and cancer: a curriculum and short student research experiences. J Cancer Educ. 2000;15(3):137-139.

32. Heimburger DC, Stallings VA, Routzahn L. Survey of clinical nutrition training programs for physicians. Am J Clin Nutr. 1998;68(6): 1174-1179.

33. Weinsier RL, Boker JR, Brooks CM, et al. Nutrition training in graduate medical (residency) education: a survey of selected training programs. Am J Clin Nutr. 1991;54(6):957-962.

34. Jackson AA. Human nutrition in medical practice: the training of doctors. Proc Nutr Soc. 2001;60:257-263. 
35. Creating an Interprofessional Workforce. Creating an Interprofessional Workforce: An Education and Training Framework for Health and Social Care in England. London: Creating an Interprofessional Workforce; 2007. Available from: http://caipe.org.uk/silo/files/cipw-fw-doc.pdf. Accessed December 1, 2013.

36. Barr H. Undergraduate Interprofessional Education. London: Centre for the Advancement of Interprofessional Education; 2003. Available from: http://www.gmc-uk.org/Undergraduate_interprofessional_education. pdf_25397207.pdf. Accessed December 1, 2013.

37. Friedman G, Kushner R, Alger-Mayer S, Bistrian B, Gramlich L, Marik PE. Proposal for medical school nutrition education: topics and recommendations. JPEN J Parenter Enteral Nutr. 2010; 34(Suppl 6):40S-46S.

38. Pearson TA, Stone EJ, Grundy SM, McBride PE, Van Horn L, Tobin BW; NAA Collaborative Group. Translation of nutritional sciences into medical education: the Nutrition Academic Award Program. Am J Clin Nutr. 2001;74(2):164-170.

39. Hark LA. Lessons learned from nutrition curricular enhancements. Am J Clin Nutr. 2006;83(4):968S-970S.

40. National Heart Lung and Blood Institute and Division of Cardiovascular Sciences. Working Group on Future Directions for Implementing Nutrition Across the Continuum of Medical and Health Professions Education and Training, and Research [webpage on the Internet] September 10-11, 2012; Bethesda, MD. Executive summary. Available from: http://www.nhlbi.nih.gov/meetings/workshops/nutrition.htm. Accessed December 1, 2013.
41. Bipartisan Policy Center. Lots to Lose: How America's Health and Obesity Crisis Threatens our Economic Future. Washington, DC: Health Program, Nutrition and Physical Activity Initiative; 2012. Available from: http://bipartisanpolicy.org/sites/default/files/5023_BPC_NutritionReport_FNL_Web_0.pdf. December 1, 2013.

42. Nightingale JM, Reeves J. Knowledge about the assessment and management of undernutrition: a pilot questionnaire in a UK teaching hospital. Clin Nutr. 1999;18(1):23-27.

43. Walsh CO, Ziniel SI, Delichatsios HK, Ludwig DS. Nutrition attitudes and knowledge in medical students after completion of an integrated nutrition curriculum compared to a dedicated nutrition curriculum: a quasi-experimental study. BMC Med Educ. 2011;11:58.

44. McGaghie WC, Van Horn L, Fitzgibbon M, et al. Development of a measure of attitude toward nutrition in patient care. Am J Prev Med. 2001;20(1):15-20.

45. Mihalynuk TV, Scott CS, Coombs JB. Self-reported nutrition proficiency is positively correlated with the perceived quality of nutrition training of family physicians in Washington State. Am J Clin Nutr. 2003;77(5):1330-1336.

46. Huang J, Yu H, Marin E, Brock S, Carden D, Davis T. Physicians' weight loss counseling in two public hospital primary care clinics. Acad Med. 2004;79(2):156-161.

47. Hiddink GJ, Hautvast JG, van Woerkum C, Fieren C, van’t Hof M. Driving forces for and barriers to nutrition guidance practices of dutch primary care physicians. J Nutr Educ. 1997;29(1):36-41.

48. Kushner RF. Barriers to providing nutrition counseling by physicians: a survey of primary care practitioners. Prev Med. 1995;24(6):546-552.
Journal of Multidisciplinary Healthcare

\section{Publish your work in this journal}

The Journal of Multidisciplinary Healthcare is an international, peerreviewed open-access journal that aims to represent and publish research in healthcare areas delivered by practitioners of different disciplines. This includes studies and reviews conducted by multidisciplinary teams as well as research which evaluates the results or conduct of such teams or

\section{Dovepress}

healthcare processes in general. The journal covers a wide range of areas and welcomes submission from practitioners at all levels, from all over the world. The manuscript management system is completely online and includes a very quick and fair peer-review system. Visit http://www.dovepress.com/testimonials.php to read real quotes from published authors. 